\title{
Genotoxicity of Alkaloid-Rich Extract from Lupinus termis Seeds
}

\author{
Marie R. Santiago Quiles ${ }^{1}$, Ilia Oquendo-Jiménez ${ }^{2}$, Diógenes Herreño-Saénz ${ }^{1}$ and \\ Mikhail D. Antoun ${ }^{2} *$
}

${ }^{I}$ Department of Pharmacology and Toxicology, School of Medicine, Medical Sciences Campus, University of Puerto Rico, San Juan, Puerto Rico, USA

${ }^{2}$ Department of Pharmaceutical Sciences, School of Pharmacy, Medical Sciences Campus, University of Puerto Rico, San Juan, Puerto Rico, USA

\begin{abstract}
The seeds of Lupinus termis are used in the Middle East and Africa as food and in folklore medicine. In traditional medicine, the seeds are reputed to be effective for diabetes. Topically, the powdered seeds are used to treat acne, and in clinical studies performed outside the U.S.A., the ethanolic extract demonstrated efficacy in the treatment of chronic hand and foot eczema. In order to evaluate these traditional uses in controlled clinical trials in the U.S.A., the Food and Drug Administration requires proof of safety of the product under investigation. Three required genotoxicity studies are described in this paper: the Reverse Mutation Assay; the Mouse Lymphoma Assay; and the Mouse Micronucleus Assay. In all three assays, the ethanolic extract of $L$. termis was found to be not genotoxic. Further toxicity studies required by the FDA will be reported in due course.
\end{abstract}

Keywords: Lupinus termis, quinolizidine alkaloids, toxicology, reverse mutation assay, mouse lymphoma assay, mouse micronucleus assay.

\section{INTRODUCTION}

Lupins (lupines) grow over a wide range throughout the world, in latitudes from $65^{\circ} \mathrm{N}$ (Iceland) to $42^{\circ} \mathrm{S}$ (Chile and New Zealand), and altitudes from sea level (Australia) to 3,800 m (Bolivia) [1]. The four major commercial species of lupins available for food consumption are: Lupinus albus L. (white lupin), L. angustifolius L. (narrow leaf or blue lupin), $L$. luteus L. (European yellow lupin), and L. mutabilis Sweet (tarwi, chocho, altramuz, Andean lupin, South American lupin, pearl lupin). In Sudan, wild varieties of L. termis Forssk. (turmus) are cultivated almost entirely for local consumption. This species is considered synonymous to L. albus L. [2].

Quinolizidine alkaloids are present in high amounts $(\geq 1 \%$ $\mathrm{w} / \mathrm{w})$ in seeds of wild or 'bitter' varieties of lupins. They are of major concern to human and animal health. The level of alkaloids in seeds or meals prepared with seeds can be reduced by de-bittering process involving soaking and washing with water several times. This is commonly practiced in the Middle East, Africa and Europe, where high alkaloid lupins, so-called 'bitter lupins' are grown. The level of alkaloids in these varieties after de-bittering is approximately $500 \mathrm{mg} / \mathrm{kg}$. The mean alkaloidal content of low-alkaloid cultivated varieties of 'sweet lupins' is on average $130-150 \mathrm{mg} / \mathrm{kg}(\leq 0.05 \%$ w/w dried seeds) $[3,4]$.

Lupins are good source of protein and lipids and have no lectins and very low content of protease inhibitors. However,

*Address correspondence to this author at the Department of Pharmaceutical Sciences, School of Pharmacy, Medical Sciences Campus, University of Puerto Rico, San Juan 00936, Puerto Rico, USA; Tel: (787) 758-2525 Ext. 5414, 1230; Fax: (787)282-7065; E-mail: mikhail.antoun@upr.edu since it is practically impossible to completely eliminate the alkaloids, these compounds may be found in flours and meals of the seeds used to prepare pastas, pastries and dairy products substitutes. Following de-bittering, seeds of $L$. albus are used in the Middle East and Europe as snack foods. In Europe, seeds of L. albus are known as 'lupini beans'. The seeds of $L$. albus are also used in traditional fermented foods such as tempe, miso and soy sauces in Indonesia and Japan. Lupin derivatives are increasingly being introduced for human consumption using flour derived from low alkaloid varieties [3].

The available data on lupin alkaloids is limited, and does not allow full characterization of the risk exposure to humans. Noteworthy is the fact that humans are more susceptible to the toxicity associated with lupin alkaloids than other species. In order to characterize further possible potential risk associated with lupin alkaloids, in the varieties used for dietary consumption, additional research is required [3, 4].

Aside from their significance as important food crops, bitter lupin seeds (having high alkaloid content) are used in traditional medicine, which is the focus of the current study. For example, powdered seeds of $L$. termis are reputed to be effective in the treatment of acne, and the seeds are also used for diabetes [5]. The ethanolic extract of these seeds demonstrated promising activity in chronic eczema in clinical trials done outside the U.S.A. [5, 6].

The U.S. Food and Drug Administration (FDA) requires extensive toxicological studies to assure adequate safety of a product, before allowing any clinical study on human subjects. This paper describes three genotoxicity studies done on the L. termis seed extract, which are part of the overall toxicological evaluation, required by the FDA, for permission to 
conduct human clinical trials to evaluate the validity of the traditional medicinal uses of these seeds $[7,8]$.

The information generated, from this study, also addresses an important gap regarding the safety long- term consumption of de-bittered white lupin as food. Of interest to note is the fact that this study was carried out on an African variety of lupin, unlike published reports which, so far, are mostly on the species and varieties growing in Australia, Europe and the U.S.A $[3,4]$. It represents the first genotoxicity study on this species [4]. The main alkaloid present in $L$. termis is (dl)-lupanine (Fig. 1), but other alkaloids have been reported in lesser or trace amounts [9, 10, 11]. Genotoxicity testing was done following a 3-battery standard recommended by the FDA and the ICH $[7,8]$ : the Salmonella typhimurium Reverse Mutation Assay (Ames test) $[12,13]$; the Mouse Lymphoma Assay [14]; and the in vivo Bone Marrow Micronucleus Test [15].

\section{EXPERIMENTAL}

All experimental protocols were approved by the Biosafety Committee and the Institutional Animal Care and Use Committee (IACUC) of the Medical Sciences Campus of the University of Puerto Rico.

\section{Cells, Culture Medium, S9 Activation System, and Chemicals}

Salmonella typhimurium strains, TA97a, TA98, TA100, TA102, TA1535 and TA1538 were purchased from Discovery Partners (Xenometric), (San Diego, CA). Postmitochondrial supernatant fraction of rat liver homogenate, Aroclor-1254-induced (S9 microsomal fraction) was purchased from Moltox Inc, (Boone, NC). The stock cell line L5178 $\mathrm{Y} \mathrm{TK}^{+/-}$was purchased from ATCC (Manassas, VA). Heat inactivated horse serum, fetal bovine serum, 4nitroquinoline-1-oxide, 5-trifluorothymidine, benzo(a)pyrene, 2-aminofluorene, biotin, L-histidine, dimethyl sulfoxide, Giemsa solution, glucose-6-phosphate, May-Gruenwald solution, normal saline, mitomycin $\mathrm{C}$, sodium chloride, potassium chloride, magnesium chloride, dextrose, nicotinamide adenine dinucleotide phosphate (NADP), sodium dihydrogen phosphate, disodium hydrogen phosphate, magnesium sulfate, citric acid monohydrate, potassium phosphate, sodium ammonium phosphate, and xylene were purchased from Sigma-Aldrich (St. Louis, MO). RPMI 1640 medium, Lglutamine, sodium pyruvate, gentamycin, fungizone, pluronic, Oxoid Nutrient Broth \#2, and Difco Agar were purchased from Fisher Scientific (Cayey, Puerto Rico).

\section{Plant Material, Extract Preparation, Lupanine Reference Alkaloid}

The variety of Lupinus termis used in this study was procured from Khartoum (Sudan). Import permits of the seeds were obtained from the U.S. Department of Agriculture, the U.S. State Department and the FDA.

Half kilogram batch of the coarsely powdered seeds was macerated for $2 \mathrm{~h}$, with $95 \%$ ethyl alcohol USP, prior to packing in a glass percolator. Following $48 \mathrm{~h}$ maceration, percolation was carried out. The process was repeated 5 times, and the alcohol removed by evaporation under reduced pressure (average yield was $12 \% \mathrm{w} / \mathrm{w}$ of extract). The total alkaloids in the extract were determined in triplicate by taking $1 \mathrm{~g}$ of the extract in $10 \mathrm{~mL} 0.1 \mathrm{~N} \mathrm{HCl}$, basifying with $20 \mathrm{~mL} 0.1 \mathrm{~N} \mathrm{NaOH}$ and extracting five times, each with 50 $\mathrm{mL}$ methylene chloride:isopropanol (3:1). The combined organic layer was evaporated to dryness to give the total alkaloids $(2.5 \% \mathrm{w} / \mathrm{w})$. Lupanine (Fig. 1), the major alkaloid, was isolated and purified following published procedures [9, $10,11]$.

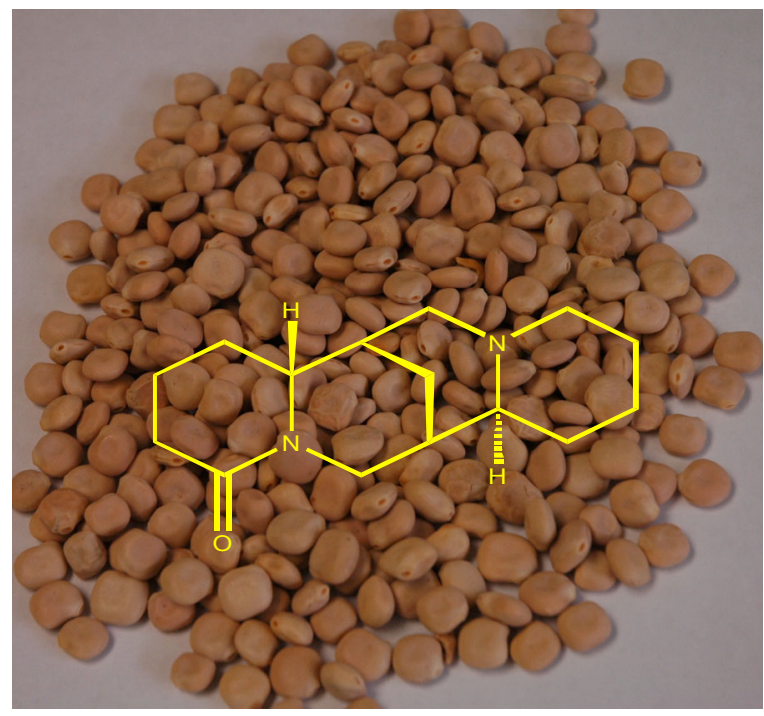

Fig. (1). Lupanine, main alkaloid found in Lupinus termis seeds as $( \pm)$ form,$(+)$ form illustrated (photograph by Reinaldo Dones Cintron).

\section{Salmonella typhimurium Mutation Assay}

Six Salmonella typhimurium strains (TA97a, TA98, TA100, TA102, TA1535 and TA1538) were grown in Oxoid Nutrient Broth No.2 [12, 13, 16]. These strains were inoculated from the frozen stock culture in $5 \mathrm{~mL}$ of nutrient broth in sterile $16 \times 125 \mathrm{~mm}$ culture tubes with loose caps. The cultures were incubated at $37^{\circ} \mathrm{C}$, and shaken at approximately $160 \mathrm{rpm}$ for $10 \mathrm{~h}$ (TA97a, TA98 and TA102) and 14 h (TA100, TA1535 and TA1538). For the mutagenicity assay, $100 \mathrm{~mL}$ of top agar was melted using a steam bath. A sterile solution $(10 \mathrm{~mL})$ of $0.5 \mathrm{mM}$ L-histidine $\mathrm{HCl} / 0.5 \mathrm{mM}$ biotin was added to the molten top agar, and mixed thoroughly. The solution was distributed into sterile 13 x 100 $\mathrm{mm}$ capped cultured tubes $(2 \mathrm{~mL} /$ tube $)$, and maintained at $43^{\circ} \mathrm{C}$ to $48^{\circ} \mathrm{C}$ in a heating block. The appropriate bacterial culture $(100 \mu \mathrm{L})$ was added to each tube followed by one of the following: $100 \mu \mathrm{L}$ of the positive control (2aminofluorene, $20 \mu \mathrm{g} / \mathrm{plate}$, or benzo(a)pyrene, $5 \mu \mathrm{g} / \mathrm{plate})$ or $100 \mu \mathrm{L}$ of $L$. termis alcoholic extract or Lupanine (the major alkaloid). An aliquot of $500 \mu \mathrm{L}$ of S9 mix (mammalian liver post-mitochondrial fraction, induced with Aroclor1254) was added to each tube being tested for mutagenicity in presence of metabolic activation. Three doses of $L$. termis alcoholic extract were used in this assay, 5 $\mu \mathrm{g} /$ plate, $20 \mu \mathrm{g} /$ plate and $100 \mu \mathrm{g} /$ plate. DMSO was used as solvent and negative control $(100 \mu \mathrm{L})$. The assay was done in triplicate and three replicates were performed for each dose of the alcoholic extract of $L$. termis. Once the components were added to $2 \mathrm{~mL}$ of top agar, the mixture was vortexed for 3 seconds at low speed, and poured onto Minimal Glucose Agar (MGA) plates. The plates were covered with 
aluminum foil; they were then inverted and incubated at $37^{\circ} \mathrm{C}$ for $48 \mathrm{~h}$. The revertant colonies per plate were then counted. These colonies were compared with the spontaneous reversion obtained in the negative control.

\section{L5178Y TK $^{+/-}$Mouse Lymphoma Assay}

Stock cultures of mouse lymphoma L5178Y $\mathrm{TK}^{+/}$cell line were grown in RPMI 1640 medium supplemented with $4 \mathrm{mM}$ L-glutamine, $1 \mathrm{mM}$ sodium pyruvate, gentamycin (100 $\mu \mathrm{g} / \mathrm{mL})$, fungizone $(2.5 \mu \mathrm{g} / \mathrm{mL})$, pluronic $(0.5 \mathrm{mg} / \mathrm{mL})$ and $10 \%$ heat-inactivated horse serum. A preliminary dose-range finding cytotoxicity experiment was performed in presence and absence of S9 mix [14, 17].

For the mutation assay, the stock cell culture $\left(1 \times 10^{7}\right)$ cells were taken, pelleted by centrifugation and re-suspended in $18.8 \mathrm{~mL}$ of RPMI with $5 \%$ horse serum and transferred to tissue culture flasks. The alcoholic extract of $L$. termis seeds $(0.2 \mathrm{~mL})$ was then added to each experimental flask. For negative control flasks, $0.2 \mathrm{~mL}$ of DMSO was added. Either $1.0 \mathrm{~mL} \mathrm{~S} 9 \mathrm{mix}$ or $1.0 \mathrm{~mL} 150 \mathrm{mM} \mathrm{KCl}$ were included depending on whether or not metabolic activation effect was investigated. Each culture flask had a final volume of $20 \mathrm{~mL}$ Benzo(a)pyrene $(2 \mu \mathrm{g} / \mathrm{mL}$ and $3 \mu \mathrm{g} / \mathrm{mL})$ was used as positive control for those samples with S9 mix. 4-Nitroquinoline1-oxide $(0.02 \mu \mathrm{g} / \mathrm{mL}$ and $0.04 \mu \mathrm{g} / \mathrm{mL})$ was used as positive control for those samples treated without S9 mix.

Following the appropriate incubation period $(4 \mathrm{~h}$ with/without S9 mix; $24 \mathrm{~h}$ confirmatory assay without S9 mix), the cell suspensions were centrifuged and washed twice with $5 \mathrm{~mL}$ of RPMI containing $10 \%$ horse serum, and re-suspended in $20 \mathrm{~mL}$ of RPMI (10\% horse serum). The cell density was determined, and dilutions performed to adjust the cell concentration to $2 \times 10^{5}$ cells $/ \mathrm{mL}$, and then allowed to grow for 2 days (expression period) at $37 \pm 1{ }^{\circ} \mathrm{C}$. During the expression period (Day 1), each flask was sub-cultured to maintain the cell concentration at $2 \times 10^{5}$ cell $/ \mathrm{mL}$. At the end of the expression period (Day 2), the cell concentration, from each flask, was re-adjusted by successive dilutions to $1 \times 10^{4}$ cell/mL using RPMI culture medium containing 20\% horse serum. An aliquot of cell suspension at $1 \times 10^{4}$ was taken to adjust the cell concentration at 8 cells $/ \mathrm{mL}$. From this final cell concentration, $0.2 \mathrm{~mL}$ was placed into each of two 96well microtitre plates. The plates were incubated for 7 days, at $37^{\circ} \pm 1{ }^{\circ} \mathrm{C}$ in $5 \% \mathrm{CO}_{2}$ atmosphere. Cell viability was calculated in presence and absence of metabolic activation compared to the positive controls.

The cell suspension at $1 \times 10^{4} \mathrm{cell} / \mathrm{mL}$ was used to determine 5-trifluorothymidine (TFT) resistance. To this cell suspension, TFT $(300 \mu \mathrm{g} / \mathrm{mL})$ was added to give a final concentration of $3 \mu \mathrm{g} / \mathrm{mL}$. Cell suspension ( $0.2 \mathrm{~mL}$ from each flask) was then pipetted into four 96-well microtitre plates (384 wells at $2 \times 10^{3}$ cells/well for each extract concentration). Each extract concentration as well as the negative control was therefore tested in 4 replicates, whereas the positive controls were tested in 8 replicates (4 replicates per positive control concentration). The plates were incubated in an atmosphere of $5 \% \mathrm{CO}_{2}$ at $37^{\circ} \pm 1{ }^{\circ} \mathrm{C}$ for 11-12 days. Wells containing viable cells were identified and counted to determine the mutant frequency. Mutation Frequency (MF) was calculated using the formula described by Clements [14].

\section{In vivo Mouse Micronucleus Assay}

Balb C male mice (5-6 weeks old; Hilltop Lab. Animals) were used to evaluate in vivo clastogenic activity and/or disruption of the mitotic apparatus by detecting micronuclei in polychromatic erythrocytes (PCE) in mouse bone marrow. The animals were randomly distributed in 6 groups of 5 animals each. Each two groups of animals received a single intra-peritoneal dose (acute exposure) of either mitomycin $\mathrm{C}$ ( $2 \mathrm{mg} / \mathrm{kg}$, positive control), or normal saline/DMSO (negative control), or $635 \mathrm{mg} / \mathrm{kg}$ of $L$. termis extract $(0.22 \mathrm{~mL}$ of $60 \mathrm{mg} / \mathrm{mL}$ extract which is $50 \%$ of the $\mathrm{LD}_{50}$ dose). One of the groups of each test substance was sacrificed by $\mathrm{CO}_{2}$ inhalation $24 \mathrm{~h}$, and the other $48 \mathrm{~h}$, post injection.

Bone marrow was harvested from five mice per group. A total of 2,000 erythrocytes/mouse were counted after staining with May-Gruenwald/Giemsa. Polychromatic (immature) erythrocytes $(\mathrm{PE})$, micronucleated polychromatic (immature) erythrocytes (PCE), and the normochromatic (mature) erythrocytes (ME) were counted. Proportion of PCE was calculated by counting a total of 200 erythrocytes [15].

\section{RESULTS AND DISCUSSION}

\section{Salmonella typhimurium Mutation Assay}

The results obtained for the Salmonella typhimurium reverse mutation assay are presented as revertants/plate, which are the revertant colonies that grew $48 \mathrm{~h}$ after treatment with either the negative or positive controls, or the alcoholic extract of $L$. termis seeds, as well as its main alkaloid lupanine with and without S9 mix. Three replicates were performed for each strain and per treatment concentration. Each replicate was performed in triplicate. The resultant revertants/plate and the standard deviation (SD) for each strain are the average of the revertants/plate for each replicate.

The data presented in Table 1 show the revertants/plate, for the positive and negative controls, the different extract concentrations and lupanine. It was observed that in all concentrations tested for the extract of $L$. termis and lupanine, the number of colonies observed compares with those obtained with the negative DMSO control.

The negative and positive controls results were reproducible and in agreement with the published literature [12, 13]. Strains TA97a, TA98, TA100, and TA1538 detect mutation of G-C base pairs at the site of mutation (seen with 2aminofluorine and benz(a)pyrene after S9 metabolic activation), whereas strain TA102 detects A:T base pairs mutation [16]. TA1535, which is TA100 without the plasmid pkM101 (this plasmid permits the detection of up to $90 \%$ of the mutagenic compounds), as anticipated, tested negative for both positive controls. The results in the samples with S9 mix, indicate that even though the ethanolic extract of $L$. termis seeds may be metabolized in the liver, its metabolites do not have a mutagenic potential, and it can therefore be concluded that the ethanolic extract of $L$. termis is neither a direct nor an indirect mutagen.

\section{L5178Y TK $^{+/-}$Mouse Lymphoma Assay}

The objective of the mouse lymphoma assay was to evaluate the ethanolic extract of $L$. termis seeds for its ability 
Table 1. Evaluation of the Genotoxicity of Lupinus termis Ethanolic Extract and Lupanine Using Salmonella typhimurium Reverse Mutation Assay

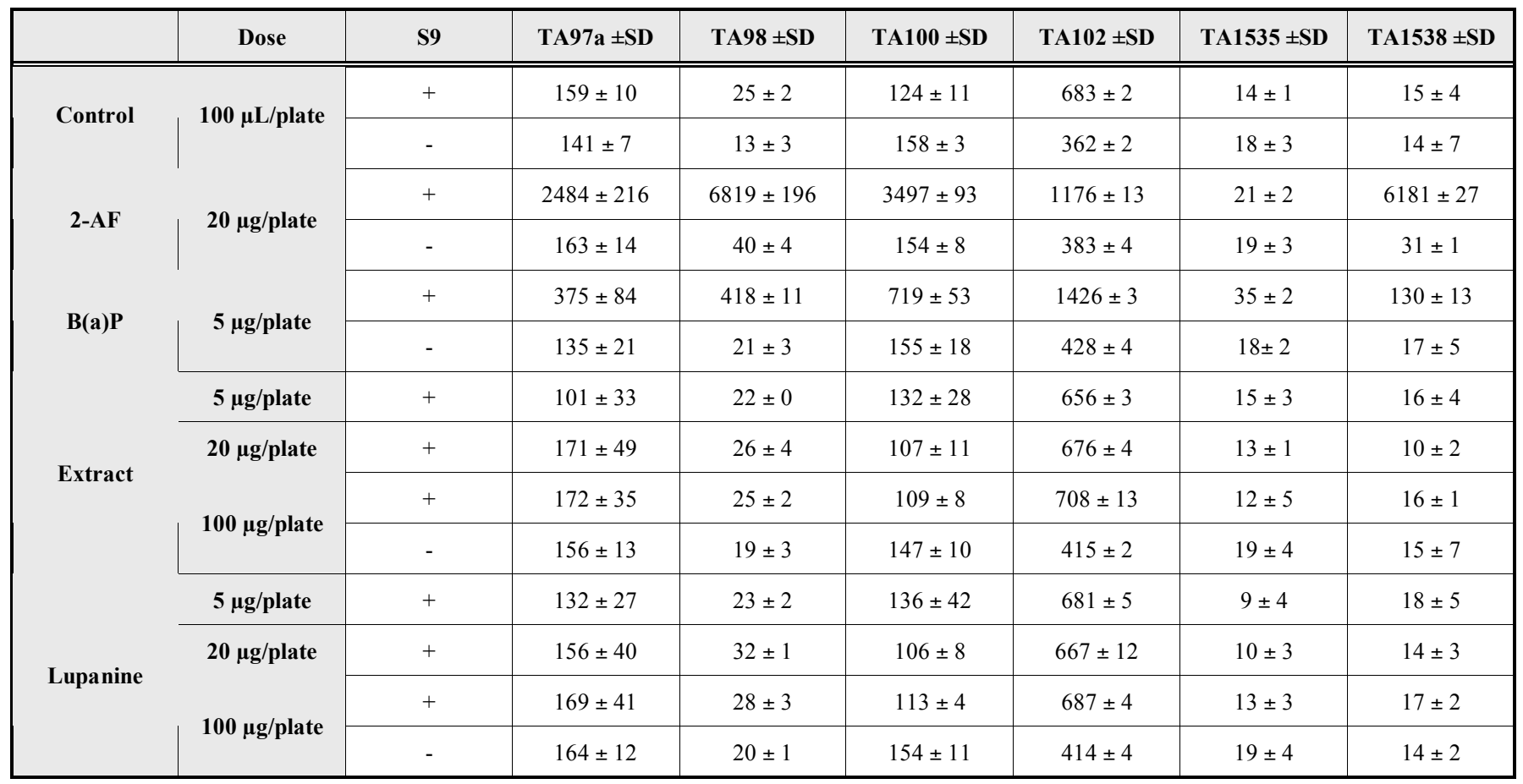

Control: Dimethylsulfoxide (negative control); 2-AF: 2-Aminofluorene (positive control); B(a)P: Benzo(a)pyrene (positive control); Extract: Lupinus termis ethanolic extract. SD: Standard Deviation; S9+: assays performed with S9 metabolic activation; S9-: assays performed without metabolic activation.

to induce forward mutations in the $\mathrm{L} 5178 \mathrm{Y} \mathrm{TK}^{+/}$mouse lymphoma cell line, as assessed by colony growth in the presence of 5-trifluorothymidine (TFT) [17]. A preliminary range finding cytotoxicity experiment was performed (data not shown) in order to establish the appropriate concentration range from toxic to non-toxic concentration. The toxic concentration was used to calculate the concentration range for the mutation assay. For the mutations assay, 2,251 $\mu \mathrm{g} / \mathrm{mL}$, which was the maximal solubility of the extract, was calculated as the "limiting dose".

The extract was not very toxic even at the highest solubility concentration $(2,251 \mu \mathrm{g} / \mathrm{mL})$. At this concentration, the relative survival was $62 \%$ in presence of $\mathrm{S} 9 \mathrm{mix}$ and $91 \%$ in absence of metabolic activation. Since no toxicity was observed following $4 \mathrm{~h}$ incubation, an extended incubation period of $24 \mathrm{~h}$ was carried out without S9 as recommended by ICH [8]. The results are shown in Table 2.

In Table 2, it can be observed that the mutation frequency of the extract (with the exception of a slight increase at the highest concentration tested with metabolic activation) did not differ from the control with and without metabolic activation after $4 \mathrm{~h}$ incubation. The mutation frequency for the positive controls (Benzo (a) pyrene (B(a)P and Nitroquinoline-oxide (NQO)) are 5 to 8 times the mutation frequency of the control. The same results are observed following the confirmatory $24 \mathrm{~h}$ incubation without activation, as recommended by the ICH [8]. These results showed that the extract of $L$. termis seeds did not cause a mutagenic effect in the mouse lymphoma cells even at the highest concentration $(2,251 \mu \mathrm{g} / \mathrm{mL})$, with and without metabolic activation.

\section{In vivo Mouse Micronucleus Assay}

The micronucleus assay was performed with $50 \% \mathrm{LD}_{50}$ of $L$. termis ethanolic extract that was determined to be 635 $\mathrm{mg} / \mathrm{Kg}$ of body weight. As can be observed in Table 3, mitomycin $\mathrm{C}$ produced a large and significant increase in the frequency of PCE, in agreement with the literature [18]. It has been recommended that for positive controls the micronucleus frequency should not be higher than $10 \%$ [19]. In the current study, the micronucleus frequency for mitomycin $\mathrm{C}$ (positive control) was found to be $2 \%$ after $24 \mathrm{~h}$ and $11 \%$ at $48 \mathrm{~h}$. The micronucleus frequency for the ethanolic extract of L. termis seeds was $0.4 \%$ at $24 \mathrm{~h}$ and $0.6 \%$ at $48 \mathrm{~h}$, compared to $0.7 \%$ in the negative control (DMSO).

To ensure absence of artifacts, that could affect the results of the micronucleus frequency, a limit is set of 5 micronucleated mature erythrocytes in a field of 2,000 erythrocytes [15]. Only 3 cells of this type were observed in a field of 2,000 erythrocytes (Table 3). For each treatment, the proportion of immature erythrocytes among total erythrocytes was in the range of $0.5-0.65$, suggesting normal production of erythrocytes during treatment $[18,20]$. The micronucleus assay demonstrated that the extract did not cause any chromosomal damage in dividing bone marrow erythroblasts under the established experimental conditions.

The results obtained through these studies clearly demonstrate that the ethanolic extract of the alkaloid-rich extract from $L$. termis seeds is not genotoxic, and not clastogenic at the concentrations intended to be evaluated for possible clinical efficacy. In addition, these results support previous results obtained from genetic toxicological studies performed on other lupin species such as L. angustifolius [4]. Further- 
Table 2. Mutation Assay of the Ethanolic Extract of Lupinus termis Seeds Using Mouse Lymphoma Cells $\left(\mathrm{L5178Y}^{+/-}\right) \mathrm{with}^{\mathrm{and}}$ without S9 Mix

\begin{tabular}{|c|c|c|c|c|c|c|}
\hline \multirow[b]{2}{*}{$\begin{array}{l}\text { Concentration } \\
(\mu \mathrm{g} / \mathrm{mL})\end{array}$} & \multicolumn{2}{|c|}{ 4-h with S9 } & \multicolumn{2}{|c|}{ 4-h without S9 } & \multicolumn{2}{|c|}{ 24-h without S9 } \\
\hline & $\%$ Viability \pm SD & $\mathbf{M F} \pm \mathbf{S D}$ & $\%$ Viability \pm SD & $\mathbf{M F} \pm \mathbf{S D}$ & $\%$ Viability \pm SD & $\mathbf{M F} \pm \mathbf{S D}$ \\
\hline 2251 & $89 \pm 7$ & $56 \pm 9$ & $89 \pm 2$ & $19 \pm 7$ & $90 \pm 4$ & $34 \pm 5$ \\
\hline 1908 & $91 \pm 4$ & $28 \pm 11$ & $84 \pm 2$ & $12 \pm 7$ & $100 \pm 5$ & $35 \pm 5$ \\
\hline 1617 & $89 \pm 3$ & $22 \pm 9$ & $81 \pm 0$ & $28 \pm 6$ & $100 \pm 9$ & $32 \pm 8$ \\
\hline 1370 & $106 \pm 2$ & $26 \pm 10$ & $88 \pm 4$ & $18 \pm 10$ & $102 \pm 12$ & $31 \pm 7$ \\
\hline 1161 & $111 \pm 0$ & $30 \pm 12$ & $85 \pm 0$ & $23 \pm 4$ & $104 \pm 15$ & $30 \pm 11$ \\
\hline 984 & $111 \pm 5$ & $25 \pm 13$ & $88 \pm 8$ & $21 \pm 6$ & $100 \pm 9$ & $27 \pm 5$ \\
\hline B(a)P $2 \mu \mathrm{g} / \mathrm{mL}$ & $81 \pm 4$ & $229 \pm 17$ & & & & \\
\hline B(a)P $3 \mu \mathrm{g} / \mathrm{mL}$ & $42 \pm 1$ & $353 \pm 34$ & & & & \\
\hline NQO $0.02 \mu \mathrm{g} / \mathrm{mL}$ & & & $83 \pm 5$ & $93 \pm 7$ & $93 \pm 3$ & $66 \pm 6$ \\
\hline NQO $0.04 \mu \mathrm{g} / \mathrm{mL}$ & & & $81 \pm 4$ & $242 \pm 15$ & $94 \pm 7$ & $202 \pm 19$ \\
\hline DMSO & --- & $39 \pm 7$ & --- & $32 \pm 5$ & --- & $26 \pm 6$ \\
\hline
\end{tabular}

MF: Mutant Frequency per $10^{6}$ viable cells; SD: Standard Deviation; B(a)P (Benzo (a)pyrone) and NQO (4-nitroquinoline-1-oxide) positive controls, DMSO (Dimethylsulfoxide) negative control.

Table 3. Micronucleus Frequency Using Bone Marrow Cells $24 \mathrm{~h}$ and $48 \mathrm{~h}$ after the Administration of Lupinus termis Ethanolic Extract (635 mg/kg of body weight), Mitomycin C and DMSO Result of each group (negative control, positive control, extract) are the average of 5 treated balb $\mathrm{C}$ mice per group

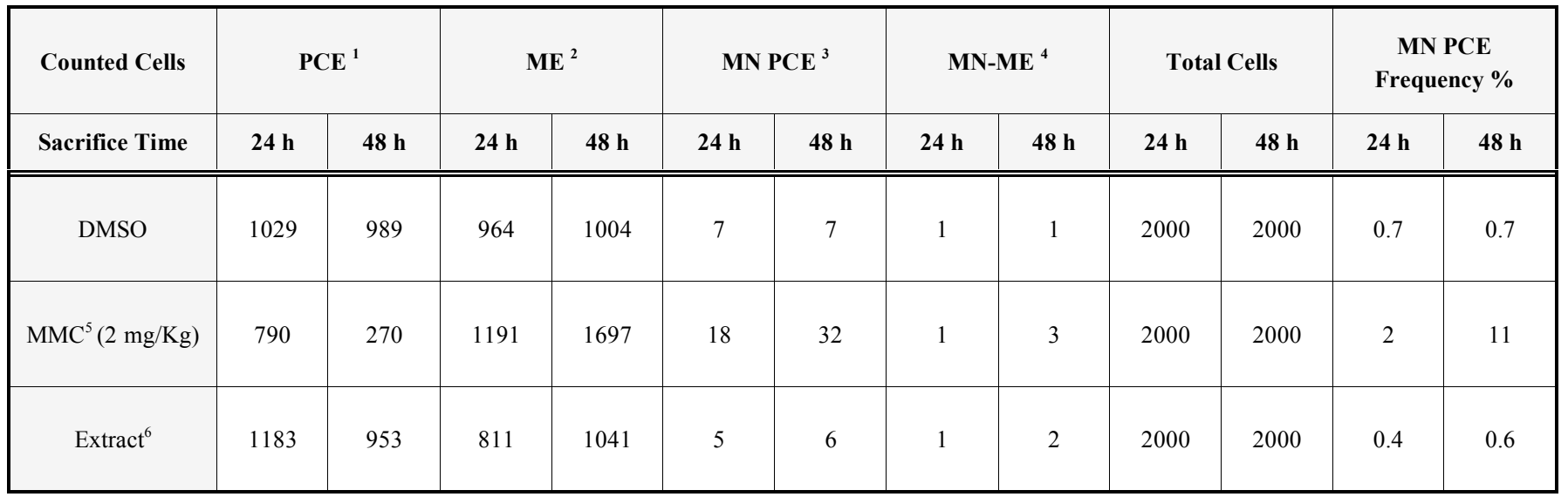

${ }^{1}$ Polychromatic Erythrocytes; ${ }^{2}$ Mature Erythrocytes; ${ }^{3}$ Micronucleated Polychromatic Erythrocytes; ${ }^{4}$ Micronucleated Mature Erythrocytes; DMSO (Dimethylsulfoxide negative control); ${ }^{5}$ Mitomycin C (positive control); ${ }^{6}$ Ethanolic extract of Lupinus termis seeds.

more, these results, together with other toxicological studies published to-date $[3,4]$ provide valuable information that can be used to support the continued use of edible lupin seeds for human and animal consumption.

\section{ACKNOWLEDGEMENTS}

This work was supported by a grant from the National Center for Complimentary and Alternative Medicine/NIH (R21-AT000961). It represents research carried out by Marie R. Santiago Quiles in partial fulfillment of the requirements for the degree of Master of Science in the Department of Pharmacology and Toxicology, School of Medicine, Univer- sity of Puerto Rico. The authors wish to acknowledge the technical support of Zulma Ramos (Department of Pharmaceutical Sciences, School of Pharmacy), William Rodríguez, Elías Sierra, Pedro Rivera and Raúl Rivera (Department of Microbiology, School of Medicine) University of Puerto Rico.

\section{REFERENCES}

[1] Baylis, J.M.; Hamblin, J. Lupins in the farming system: a survey of production. In Proceedings of the Fourth International Lupin Conference, Geraldton, Western Australia, August 15-26; published for the International Lupin Association by the Department of Agriculture, 3 Baron-Hay Court, South Perth, Western Australia 6151; 1986; pp. 161-172. 
[2] Porcher, M.H. Sorting Lupinus names (Multilingual Multiscript Plant Name Database) 2007. http://www.ars-grin.gov/misc/mmpnd/ Lupinus.html Date created: 15/11/1999. Last modified: 28/05/2007. (C) 1995-2003 The University of Melbourne, Australia, (Accessed May 7, 2007).

[3] Australia New Zealand Food Authority. Lupin alkaloids in food. A toxicological review and risk assessment. Technical Report Series No.3, 2001, pp 1-21. ANZFA Australia, PO Box 7186, Canberra BC ACT 2610, Australia; http://www.foodstandards.gov.au/ srcfiles/TR3.pdf (Accessed May 7, 2010).

[4] Alkaloids in edible lupin seeds. A toxicological review and recommendations. Kirsten Pilegaard and Jørn Gry. TemaNord 2008:605; Nordic Council of Ministers, Copenhagen, 2008; pp 14, 52. http://www.norden.org/da/publikationer/publikationer/2008-605 (Accessed May 7, 2010).

[5] Antoun, M.D.; El-Khawad, A.O.; Taha, O.M.A. Studies on Sudanese Medicinal Plants I. The effect of an extract of Lupinus termis seeds in chronic eczema. Lloydia, 1977, 40(4), 337-339.

[6] Antoun, M.D.; Taha, O.M.A. Studies on Sudanese Medicinal Plants II. Evaluation of an extract of Lupinus termis seeds in chronic eczema. J. Nat. Prod., 1981, 44(2), 179-183.

[7] U.S. Food and Drug Administration, Red Book 2000, Toxicological Principles for the Safety of Food Ingredients: IV.C.1 Short-term Tests for Genetic Toxicity. http://www.fda.gov/Food/Guidance ComplianceRegulatoryInformation/GuidanceDocuments/FoodIngre dientsandPackaging/Redbook/ucm078310.htm

[8] Genotoxicity: A standard battery for genotoxicity testing of pharmaceuticals. International Conference on Harmonization of Technical Requirements for Registration of Pharmaceuticals for Human Use. 1997, pp. 1-7. http://www.ich.org/LOB/media/MEDIA494.pdf (Accessed May 13, 2010)

[9] Mohamed, M.H.; Saito, K.; Murakoshi, I.; Kadry, H.A.; Khalifa, T.I.; Ammar, H.A. A new lupine alkaloid, (-)- $\Delta^{5}$ dehydromultiflorine from the seeds of Lupinus termis. J. Nat. Prod., 1990, 53(6), $1578-1580$.
[10] Mohamed, M.H.; Saito, K.; Kadry, H.A.; Khalifa, T.I.; Ammar, H.A.; Murakoshi, I. Lupin alkaloids from the seeds of Lupinus termis. Phytochemistry, 1991, 30(9), 3111-3115.

[11] Mohamed, M.H.; El-Shorbagi, A-N.A. ( \pm -Termisine, a novel lupine alkaloid from the seeds of Lupinus termis. J. Nat. Prod., 1993, 56(11), 1999-2002.

[12] Maron, D.M.; Ames, B.N. Revised method for the Salmonella mutagenicity test. Mutat. Res., 1983, 113(3-4), 173-215.

[13] Mortelmans, K.; Zeiger, E. The Ames Salmonella/microsome mutagenicity assay. Mutat. Res., 2000, 455 (1-2), 29-60.

[14] Clements, J. The mouse lymphoma assay. Mutat. Res., 2000, 455(1-2), 97-110.

[15] Schmid, W. The micronucleus test. Mutat. Res., 1975, 31, 9-15.

[16] Levin, D.E.; Hollstein, M.; Christman, M.F.; Schweirs, E.A. Ames, B.N. A new Salmonella tester strain (TA102) with AXT base pairs at the site of mutation detects oxidative mutagens. Proc. Natl. Acad. Sci. U.S.A., 1982, 79(23), 7445-7449.

[17] Clive, D.; Johnson, K.O.; Spector, J.F.; Batson, A.G.; Brown, M.M. Validation and characterization of the $\mathrm{L} 5178 \mathrm{Y} / \mathrm{TK}^{+/}$mouse lymphoma mutagen assay system. Mutat. Res., 1979, 59(1), 61108.

[18] MacGregor, J.T.; Heddle, J.A.; Hite, M.; Margolin, B.H.; Ramel, C.; Salamone, M.F.; Tice, R.R.; Wild, D. Guidelines for the conduct of micronucleus assays in mammalian bone marrow erythrocytes. Mutat. Res., 1987, 189(2), 103-112.

[19] Mavournin, K.H.; Blakey, D.H.; Cimino, M.C.; Salamone, M.F.; Heddle, J.A. The in vivo micronucleus assay in mammalian bone marrow and peripheral blood. A report of the U.S. Environmental Protection Agency Gene-Tox Program. Mutat. Res., 1990, 239(1), 29-80.

[20] Hayashi, M.; Tice, R.R.; MacGregor, J.T.; Anderson, D.; Blakey, D.H.; Kirsh-Volders, M.; Oleson, F.B.; Jr.; Pacchierotti, F.; Romagna, F.; Shimada, H.; Sutou, S.; Vannier, B. In vivo rodent erythrocyte micronucleus assay. Mutat. Res., 1994, 312(3), 293304.

(c) Santiago Quiles et al.; Licensee Bentham Open.

This is an open access article licensed under the terms of the Creative Commons Attribution Non-Commercial License (http://creativecommons.org/licenses/ by-nc/3.0/) which permits unrestricted, non-commercial use, distribution and reproduction in any medium, provided the work is properly cited. 